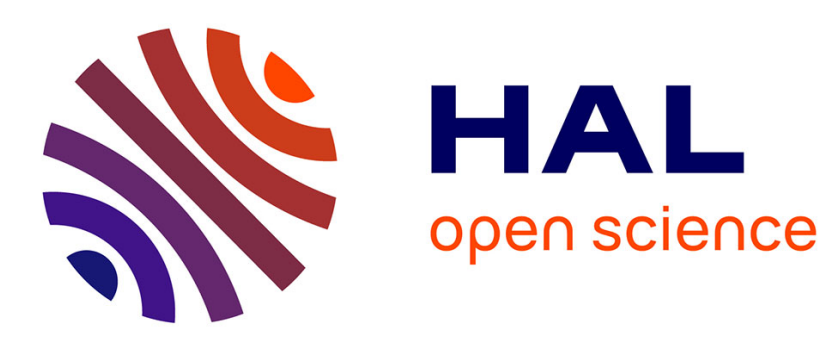

\title{
Numerical Simulation of the Impact of Projectiles on Thin Aluminium Plates
}

J. Pérez-Castellanos, R. Cortés, J. Fernandez-Saez, C. Navarro

\section{To cite this version:}

J. Pérez-Castellanos, R. Cortés, J. Fernandez-Saez, C. Navarro. Numerical Simulation of the Impact of Projectiles on Thin Aluminium Plates. Journal de Physique IV Proceedings, 1997, 07 (C3), pp.C3711-C3-716. 10.1051/jp4:19973121 . jpa-00255407

\section{HAL Id: jpa-00255407 https://hal.science/jpa-00255407}

Submitted on 1 Jan 1997

HAL is a multi-disciplinary open access archive for the deposit and dissemination of scientific research documents, whether they are published or not. The documents may come from teaching and research institutions in France or abroad, or from public or private research centers.
L'archive ouverte pluridisciplinaire HAL, est destinée au dépôt et à la diffusion de documents scientifiques de niveau recherche, publiés ou non, émanant des établissements d'enseignement et de recherche français ou étrangers, des laboratoires publics ou privés. 


\title{
Numerical Simulation of the Impact of Projectiles on Thin Aluminium Plates
}

\author{
J.L. Pérez-Castellanos, R. Cortés, J. Fernández-Sáez and C. Navarro \\ Department of Engineering, Escuela Politécnica Superior, Universidad Carlos III de Madrid, \\ c/Butarque 15, 28911 Leganés, Madrid, Spain
}

\begin{abstract}
Résumé.- L'objet de cet article est l'etude numérique du comportement de plaques minces d'aluminium soumises aux impacts normals de projectiles rigides en acier, à des vitesses d'impact comprises entre $41 \mathrm{~m} / \mathrm{s}$ et $93 \mathrm{~m} / \mathrm{s}$. Les deux situations de perforations et non-perforation on été considérées. Le but de l'etude est de vérifier la correlation entre les predictions numériques de la force résistante de la cible, et les mesures experimentales obtenues avec l'anemometrie lasser-Doppler. C'est une nouvelle approche à cause des difficultés poru mesurer experimentalement la force d'impact. Les estimations de la force résistante de la cible. obtenues numériquement, sont similaires à celles obtenues experimentalment. L'étude numérique doit donc être considerée comme fiable.
\end{abstract}

\begin{abstract}
Summary. - In this paper a numerical study of the behaviour thin aluminium plates impacted normally by hard steel projectiles at impact velocities rabging from $41 \mathrm{~m} / \mathrm{s}$ and $93 \mathrm{~m} / \mathrm{s}$ is made. The two situations of perforation and non-perforation are considered. The aim of the study is to check the reliability of the numerical predictions of the resistance force of the target compared with experimental measurements obtained by laser-Doppler anemometry. This is a new approach since the impact force can rarely be measured experimentally. The estimations of the resistance force of the target obtained numerically were similar to those obtained experimentally, so the approximations made in the analysis may be considered reliable.
\end{abstract}

\section{INTRODUCTION}

Studies of ballistic impact are intended to provide qualitive and quantitative estimations of the behaviour of a structure of a given material impacted by a projectile. Problems of ballistic impact are of great interest, but their setting up, formulation and solution are usually very complex. For example, with regard to the material of the impacted structure, existing models of mechanical behaviour are based and tested in conditions that may not be at all representative of those existing in an actual ballistic impact. This inconsistency of the models is even more serious when such problems arise as dynamic cracks which are difficult to model accurately. The micromechanisms of dynamic failure are now well known, but the models available are not only excessively complicated but are incomplete and unsuitable for generalization. The models used in numerical analysis are usually simple, based on a limited number of parameters, but even so, they can be applied to conditions of ballistic impact. To be adequate to the problem, their numerical predictions must be compared whenever possible with the experimental data provided by new techniques.

The evolution of experimental techniques now makes it possible to record the history of some of the incidents of ballistic impact. For example, the position of the projectile and of the target can be determined from X-rays, and the speed of the free surface of the target by interferometry. But it is much more difficult to measure experimentally such magnitudes as the strains and stresses in the impact zone; there are now sensors that measure the impact pressure but they are difficult to use and the results are limited to short intervals. This real difficulty of measuring the important magnitudes (strain and stress) in the impacted material also limits the process of comparing and contrasting the numerical models.

Recent experimental techniques have made it possible to record the penetration force on 
impact, and this is of great practical importance to both numerical and engineering models. The penetration force is a key parameter of the ballistic behaviour of an armour, and the engineering models are simplified tools that can predict, among other parameters, the penetration force history. Having experimental measurements of the force of interaction between projectile and target makes it possible to evaluate the models.

The experimental determination of force history in projectile impact has been attempted by several authors. Liss \& Goldsmith, 1984, [3] and Levy \& Goldsmith, 1984, [4] used a quartz transducer attached to the tail of the projectile to measure the force history, and Virostek et al. [6], adapted the technique in 1987 to include oblique impact. It was found in such works that the effect of wave travelling makes difficult the accuracy force estimation, and this problem has not yet been properly solved. Another method tried by Bless et al. [1] in 1978 was to fire a target against an instrumented projectile, but the problem of the wave travelling was encountered again. An optical displacement system of measurement was used by Zhu et al. in 1992 [7], but the double differentiation of the displacement history again gave rise to inaccuracies in the calculation. More recently, laser-Doppler anemometry has been used to record the velocity of a projectile during the penetration process; in the path of the projectile, two coherent rays, generally laser, form an ellipsoidal region in which there are bands of interference. When the projectile crosses each of these bands, the different intensities of dispersed light are detected and recorded. The frequency of the changes in the intensity of the light is proportional to the instantaneous velocity of the particle perpendicular to the bands. The laser-Doppler anemometry method requires comparison with independent numerical or experimental results to assess its efficacy. This technique, that requires the filtration of the highest frequencies and then a simple differentiation to obtain the impact force, should provide more reliable records as pointed out by Wu et al.,1994 [8]. These authors present experimental records of the normal impact of a hard steel projectile on a thin aluminium plate at velocities between $41 \mathrm{~m} / \mathrm{s}$ and $93 \mathrm{~m} / \mathrm{s}$. The plate was penetrated without any plastic deformation of the projectile.

The first aim of this study was to obtain numerical estimations of the penetration force, to compare them with the experimental results obtained by Wu et al (1994) [8] and assess the reliability of both the numerical and the experimental methods. They were shown to compare quite well, so the hypotheses adopted may be taken as acceptable.

\section{NUMERICAL MODELLING}

In this paper, a numçerical analysis is made of the normal impact of a high-strength steel projectile on a $1 \mathrm{~mm}$ thick aluminium plate. The projectile is a hemispherically-tipped cylinder, $38.5 \mathrm{~mm}$ long and $12.7 \mathrm{~mm}$ in diameter and weighing $35.6 \mathrm{~g}$..

The modelling used the AUTODYN-2D computer code (Cowler \& Birnbaum, 1989 [2]) with axial symmetry conditions. The target was modelled with a mesh of 1331 nodes and 1200 elements, and the projectile with a mesh of 532 nodes and 468 elements. The projectile was considered to show linear elastic behaviour since it had not been plastically deformed during the experiment. The mechanical properties of the 6061-T6 aluminium were taken from the literature, incorporating the effect of the strain rate on the flow stress of the material (Vaziri et al.,1993 [4]). The impact velocities considered were $41.4 \mathrm{~m} / \mathrm{s}, 53.0 \mathrm{~m} / \mathrm{s} 63.3 \mathrm{~m} / \mathrm{s} 70.5 \mathrm{~m} / \mathrm{s}, 82.8 \mathrm{~m} / \mathrm{s}$ and 93.5 $\mathrm{m} / \mathrm{s}$. In each of these cases, the lineal momentum history of the projectile was recorded, which gave the penetration force by simple derivation. This reduces the scattering of the data for this force well below the level of scattering shown in the same calculation based on the velocity at a given point of the projectile. It was observed, as in the experimental method, that the evolution 
of elastic waves in the projectile gives rise to considerable variations of instantaneous speed, and this rules out any accurate determination of the impact force by the differentiation of velocity histories. On the other hand, since the curve of the linear momentum of the projectile is much smoother than the curves of velocity at a given point of the trajectory, the wave travelling effect is negligible and the curves for penetration force/time are much smoother.

For the aluminium, a simple fracture criterion was initially adopted on the basis of a critical value for the plastic deformation. In a second phase, the criterion adopted was that of a damage increase with plastic strain, relating a damage parameter value to the value of the effective plastic deformation. A linearly damage function with plastic strain was adopted. The analytical expression of the ratio of damage (D) to deformation $(\epsilon)$ is as follows:

$$
\begin{gathered}
\left.\mathrm{D}=0 \text { if } 0<\epsilon<\epsilon_{1}\right) \\
\mathrm{D}=\left(\epsilon-\epsilon_{1}\right) /\left(\epsilon_{2}-\epsilon_{1}\right) \text { if } \epsilon_{1}<\epsilon<\epsilon_{2} \\
\mathrm{D}=1 \text { if }\left(\epsilon>=\epsilon_{2}\right)
\end{gathered}
$$

The yield stress of the material is expressed as $\sigma_{Y}=\sigma_{0}$ (1-D), the bulk modulus as $K=$ $\mathrm{K}_{0}(1-\mathrm{D})$ and the shear modulus was computed as $\mathrm{G}=\mathrm{G}_{0}(1-\mathrm{D})$.

\section{RESULTS AND COMMENTS}

Figs. 1 - 6 show simultaneously the experimental and numerical graphs of the penetration force history, using the fracture criterion of a critical value of plastic deformation for the impact velocities considered. Curve 1 correspond to an arrest case, curve 2 to the ballistic limit, and curves 3-6 to cases of perforation. The agreement is better also in cases of arrest and in that of balistic limit (Fig 1-2), while it tails off as the impact velocity increases (Fig 3-6).

Fig 7-10 show simultaneously the experimental and numerical records of the penetration force as a function of time - records obtained with the fracture criterion based on a critical value of accumulated damage - for the impact velocities in cases of perforation. As in the case of the rupture criterion based on plastic strain, agreement between the simulated and experimental methods is fairly good, somewhat better than that obtained when plastic strain controls the rupture of material.

In the cases of ballistic arrest, agreement between simulation and experimentation is fairly good throughout, though with some minor discrepancies. The first is that in the numerical model the load rises sharply from zero to a point at which the penetration force increases more slowly. This is not evident in the experimental record in which the increase is gradual from the moment of contact. In addition, the numerical model records the oscillations of the wave travelling, which were probably filtered out in the experiments. Even so, agreement is good enough to show that the numerical model has retained the essential elements of behaviour of the system. It is also clear that laser-Doppler anemometry is a reliable technique to estimate the penetration force of a projectile. It does use a filtering that eliminates some of the detail of the numerical method, but it records the most important aspects of the force history.

At an impact velocity of $53 \mathrm{~m} / \mathrm{s}$, the mid-point between non-penetration and penetration by the projectile, agreement is also good with regard to impact force.

Rupture of the target, however, usually produces a considerable numerical noise related to the sudden stress fluctuation caused when failure takes place in the target alls. This complicates the 
comparison with the experimental results but it is seen that the general trend of the force is similar. As the impact velocity rises, agreement is less evident. At the same impact velocity, there is better agreement for a rupture criterion based on a damage evolution model, which suggests that this type is perhaps more suitable for the analysis. The degree of improvement in this case varies with the impact velocity, so a breakage criterion must be determined that approximates the point of the penetration force history at which the target starts to break to a similar adjustment for all the cases studied. A breakage model in which the damage depended also on the velocity of deformation would be more complete. There is no doubt that the result of this analysis can be improved, and further investigation is required. In particular Table I shows the critical values of plastic strain and of parameters $G_{1}$ and $G_{2}$ for the damage evaluation model used.

Table I

\begin{tabular}{|c|c|c|c|}
\hline $\mathrm{v}(\mathrm{m} / \mathrm{s})$ & $\breve{G}$ & $\mathrm{G}_{1}$ & $\mathrm{G}_{2}$ \\
\hline 63 & 0.8 & 0.79 & 0.81 \\
\hline 70 & 0.8 & 0.72 & 0.77 \\
\hline 82 & 0.6 & 0.55 & 0.6 \\
\hline 93 & 0.6 & 0.52 & 0.57 \\
\hline
\end{tabular}

This table confirms the previous statement, in the sense that in order to improve the agreement between analysis and experiment, the fracture parameters must be made dependent upon the impact velocity (i.e. the strain rate). Furthermore, it can be seen that the fracture parameter values decrease as the umpact velocity increases, for both type of model used.

\section{CONCLUSIONS}

This work presents a numerical study of the normal impact of a steel projectile on a thin aluminium plate, estimating the penetration force histories at different impact velocities and using different rupture models for the target material. Fairly good agreement is observed between the experimental results and those of the numerical predictions, especially in the absence of rupture. Agreement when the target is perforated by the projectile (material damage), although it is sufficient, it can be somewhat improved when the model is based on damage evolution. In any case, the fracture parameter values seen to decrease with the impact velocity.

\section{BIBLIOGRAFIA.}

[1] Bless, S.J., Barber, J.P., Bertke, R.S. y Swift, H.F., Penetration mechanics of yawed rods, Int. J. Engng. Sci., Vol. 16, pp. 829-834 (1978).

[2] Cowler, M.S. y Birnbaum, N.K., AUTODYN User's manual, Century Dynamics Incorporated, 903 Paramount Road, Oakland, CA 94610, U.S.A. (1989).

[3] Liss, J. y Goldsmith, W., Plate perforation phenomena due to normal impact by blunt cylinders, Int. J. Impact Engng., Vol. 2, pp. 37-64 (1984). 
[4] Levy, N. y Goldsmith, W., Normal impact and perforation of thin plates by hemispherically-tipped projectiles- II Experimental results, Int. J. Impact Engng., Vol. 2, pp. 229-324 (1984).

[5] Vaziri, R., Delfosse, D., Pageau, G. y Poursartip, A., High speed impact response of particulate metal matrix composite materials- An experimental and theoretical investigation, Int. J. Impact Engng., Vol. 13, pp. 329-352 (1993).

[6] Virostek, S.P., Dual,J. y Goldsmith, W., Direct force measurements in normal and oblique impact of plates by projectiles, Int. J. Impact Engng., Vol. 6, pp. 247-269 (1987).

[7] Zhu, G. Goldsmith, W. y Dharan, C.H.K., Penetration of laminated Kevlar by projectilesII. Analytical model, Int. J Solids Struct., Vol. 29, pp.421-436 (1992).

[8] Wu, E., Sheen, H.J., Chen, Y.C. y Lang, L.C., Penetration force measurement of thin plates by laser Doppler anemometry, Exp. Mech., Vol.

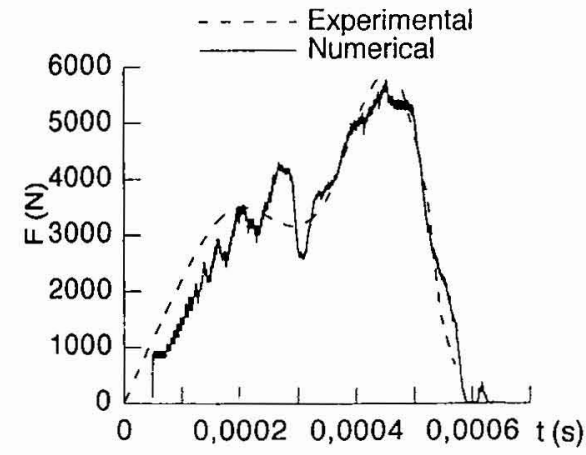

Figure 1. Impact velocity of $41.4 \mathrm{~m} / \mathrm{s}$. Rupture criterion based on plastic strain

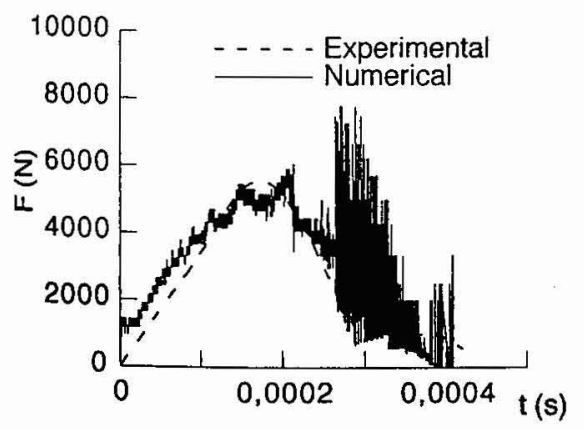

Figure 3. Impact velocity of $63.3 \mathrm{~m} / \mathrm{s}$. Rupture criterion based on plastic strain

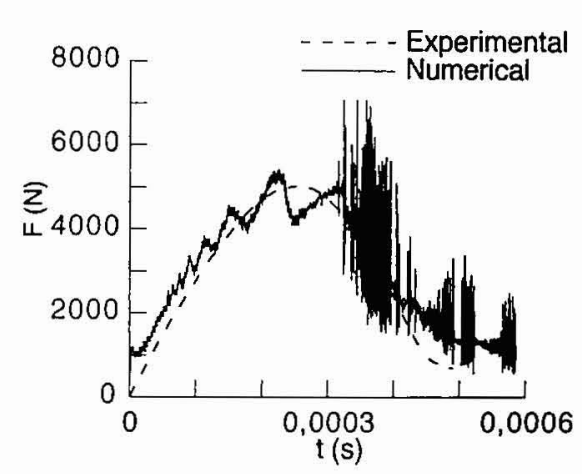

Figure 2. Impact velocity of $53.0 \mathrm{~m} / \mathrm{s}$. Rupture criterion based on plastic strain

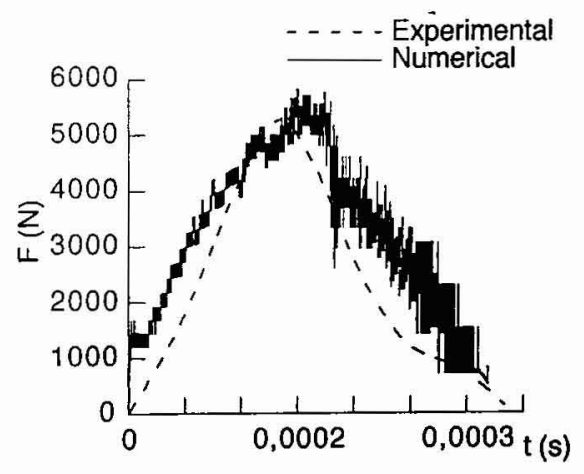

Figure 4. Impact velocity of $70.5 \mathrm{~m} / \mathrm{s}$. Rupture criterion based on plastic strain 


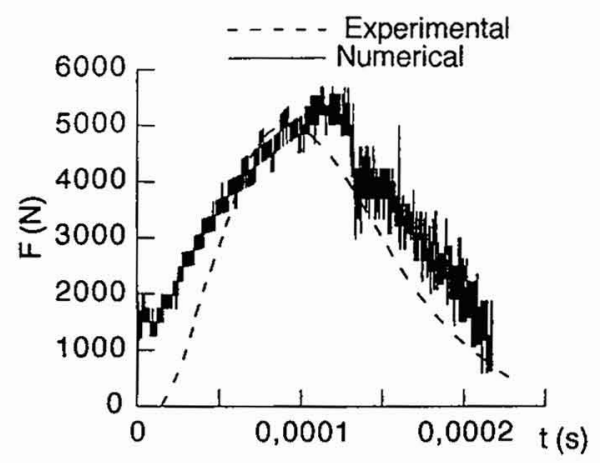

Figure 5. Impact velocity of $82.8 \mathrm{~m} / \mathrm{s}$. Rupture criterion based on plastic strain

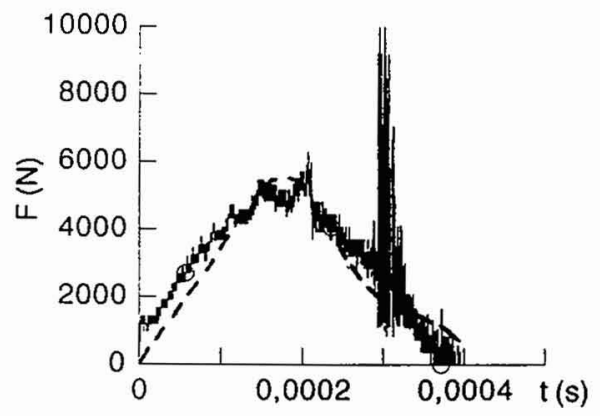

Figure 7. Impact velocity of $63.3 \mathrm{~m} / \mathrm{s}$. Rupture criterion based on critical damage

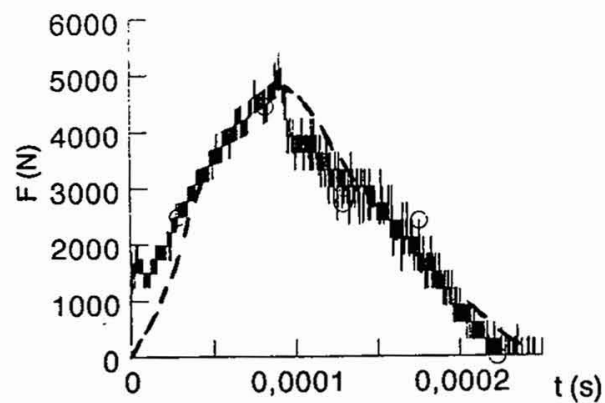

Figure 9.- Impact velocity of $82.8 \mathrm{~m} / \mathrm{s}$. Rupture criterion based on critical damage

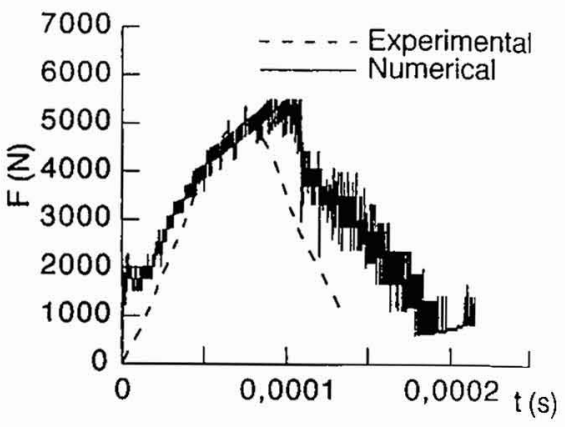

Figure 6. Impact velocity of $93.5 \mathrm{~m} / \mathrm{s}$. Rupture criterion based on plastic strain

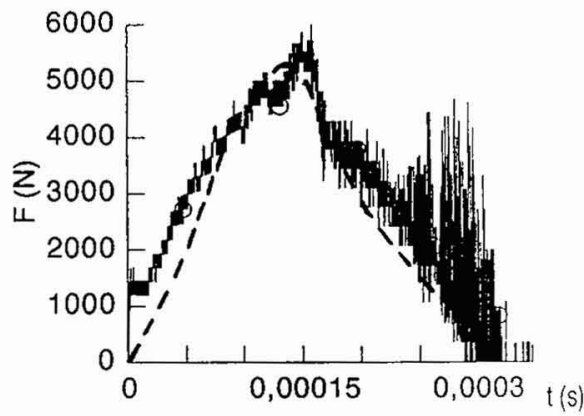

Figure 8- Impact velocity of $70.5 \mathrm{~m} / \mathrm{s}$. Rupture criterion based on critical damage

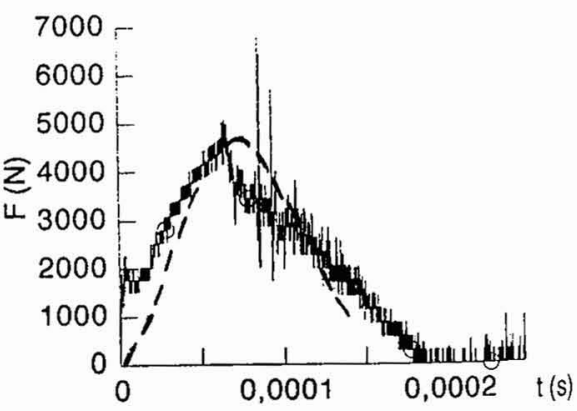

Figure 10.- Impact velocity of $93.5 \mathrm{~m} / \mathrm{s}$. Rupture criterion based on critical damage 